\title{
Correction to: Validated HIV Knowledge Scales for Use with Adults and Adolescents: A Systematic Review
}

\author{
J. L. Stewart ${ }^{1}\left(\right.$ D . Deshira D. Wallace ${ }^{2} \cdot$ Abby Nance $^{1} \cdot$ Christine A. Schalkoff $^{2} \cdot$ Breana J. Uhrig Castonguay $^{3}$. \\ Laura Widman ${ }^{1} \cdot$ Michael P. Carey ${ }^{4,5,6}$. Carol E. Golin ${ }^{2,3}$
}

Published online: 17 November 2021

(c) Springer Science+Business Media, LLC, part of Springer Nature 2021

\section{Correction to: AIDS and Behavior \\ https://doi.org/10.1007/s10461-021-03521-4}

The original version of this article unfortunately contained an error, and it has been corrected with this erratum. The title mistakenly included the word "Youth" where it should have been "Adults."

The Original article has been corrected.
The original article can be found online at https://doi.org/10.1007/ s10461-021-03521-4.

\section{J. L. Stewart}

j_stewart@ncsu.edu

1 Applied Social and Community Psychology Program, Department of Psychology, North Carolina State University, 640 Poe Hall, Campus, Box 7650, Raleigh, NC 27695-7650, USA

2 Department of Health Behavior, Gillings School of Global Public Health, University of North Carolina at Chapel Hill, 302 Rosenau Hall, 135 Dauer Drive, CB7440, Chapel Hill, NC 27599, USA
Publisher's Note Springer Nature remains neutral with regard to jurisdictional claims in published maps and institutional affiliations.
3 Department of Medicine, School of Medicine, University of North Carolina at Chapel Hill, 100 Manning Drive, Chapel Hill, NC 27599, USA

4 Center for Behavioral and Preventive Medicine, The Miriam Hospital, 164 Summit Avenue, Providence, RI 02903, USA

5 Department of Psychiatry and Human Behavior, The Warren Alpert Medical School of Brown University, Providence, RI, USA

6 Department of Behavioral and Social Sciences, School of Public Health, Brown University, Providence, RI, USA 